\title{
The use of metallic endoprostheses in interventional radiology
}

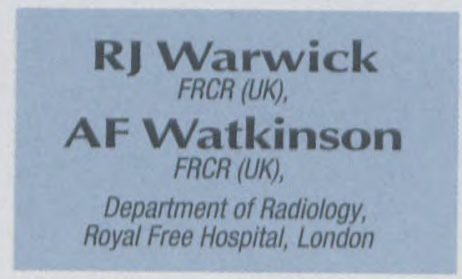

\section{Introduction}

The use of metallic endoprostheses has advanced rapidly since 1969 when Charles Dotter first described the implantation of a spiral stent via a percutaneous route to maintain a patentlumen. ${ }^{1}$ Initial problems arose from early occlusion but rapid advances and the use of various materials and configurations have increased the indications and use of metal stents throughout the body. Initial use was in the vascular system with later extension to the gastrointestinal, biliary, and respiratory systems. Metallic endoprostheses in current use are manufactured from a variety of alloys and are either self expanding or balloon expandable.

\section{Balloon expandable endoprostheses}

\section{ThePalmaz stent}

This is a balloon expandable tubular meshwork of annealed steel. This is deployed by inflation of a coaxial balloon system which has been mounted using a special crimping tool and does not expand further when the balloon has been deflated. It has been widely used since 1987 in the vascular system ${ }^{2}$ (both arterial and venous) and also for Transjugular Intrahepatic Portosystemic Shunting(TIPS) ${ }^{3}$. The stent is manufactured from stainless steel and has an electropolished surface which reduces thrombogenicity. When expanded a diamond lattice shape forms (Figure la-d), the struts of which embed in the vessel wall and endothelialisation can occur. The stent is

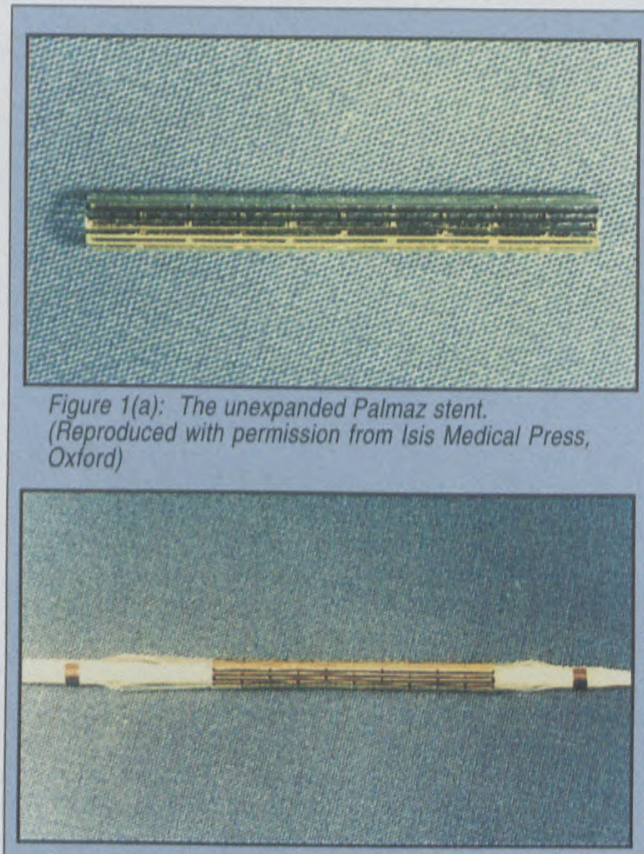

Figure 1(b): The stent has been mounted coaxially onto a balloon system. A special crimping tool ensures this is secure and will not dislodge on introduction. (Reproduced with permission from Isis Medical Press, Oxford)

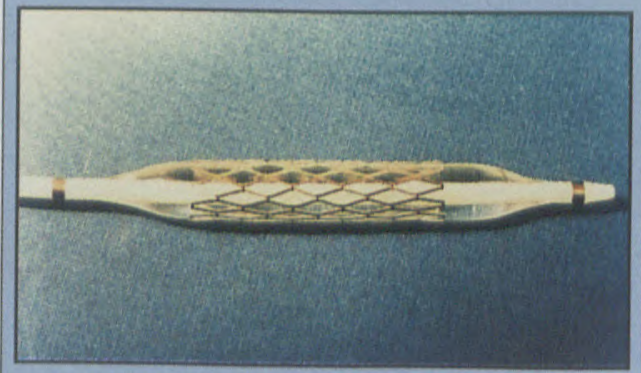

Figure (c): On balloon inflation the stent expands to the balloon diameter. (Reproduced with permission from Isis Medical Press, Oxford)

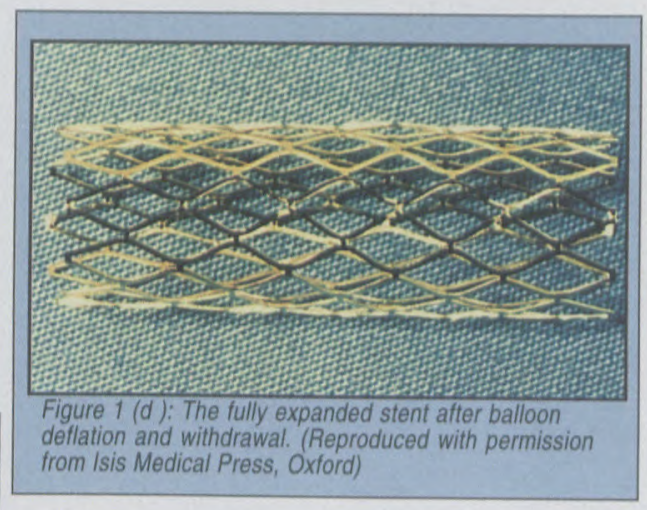

limited by little longitudinal flexibility but accurate placement is aided by only a small amount of shortening. Recent development of this stent includes a heparin coating, which has potential use in low flow vessels, and articulated stents to increase flexibility.

\section{Strecker stent}

The original Strecker stents were a balloon expandable endoprostheses made of tantalum which have been in use since 1987. ${ }^{4}$ (Figure 2) More recently a nitinol

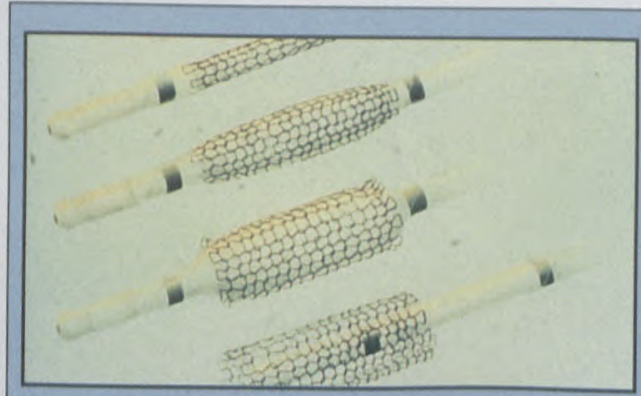

Figure 2: The original balloon expandable Strecker tantalum stent. An important feature is that both ends of the stent remain contained by thin walled sialastic sleeves until full balloon inflation. This prevents dislodgement on introduction and positioning. (Reproduced with permission from Isis Medical Press, Oxford) 


\section{from page 8}

Strecker stent has been developed. The design for both materials is fundamentally the same. The stent is made from a metallic monofilament knitted into a tubular mesh of loosely connecting loops. The main advantage of this stent is its increased flexibility and compressibility, both radial and longitudinal and in the expanded and non expanded state which makes its use possible in tortuous vessels. Although originally use was in the vascular system, Strecker stents have been deployed in the genitourinary, gastrointestinal and biliary systems.

Tantalum is less thrombogenic than copper or stainless steel and this is enhanced by surface electropolishing. ${ }^{5}$ The stent is well seen fluoroscopically as it is relatively radiodense and due to its magnetic properties it is also MRI compatible.

\section{Self expanding endoprostheses}

\section{Nitinol stents}

Nitinol is a alloy of nickel and titanium which expands and contracts under the influence of changes in temperature. ${ }^{6}$ Heat treatment during manufacture enables a shape memory to be gained so that it can be used to make thermoreactive self expanding stents which include the Strecker Elastalloy Ultraflex ${ }^{\text {TM }}$ (Figure3). Other self

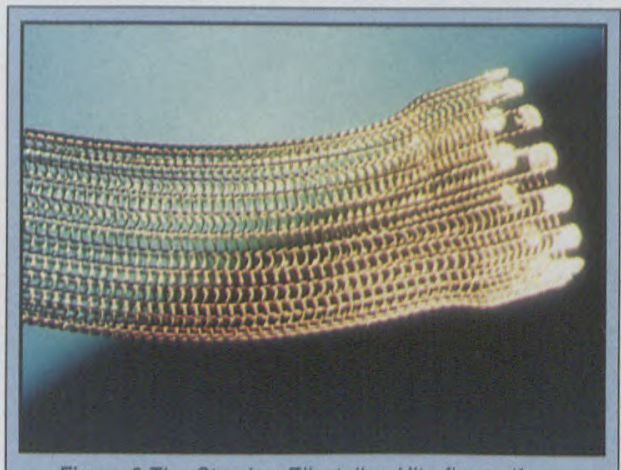

Figure 3:The Strecker Ellastalloy Ultraflex self expanding nitinol oesophageal endoprosthesis.

expandingnitinol stents are the Memotherm (Figure4a-b), and the Craggstent(Figure 5a).

The Memotherm stent has been available since 1993 and is made from a single
Figure 4:The self expanding nitinol Memotherm endoprosthesis

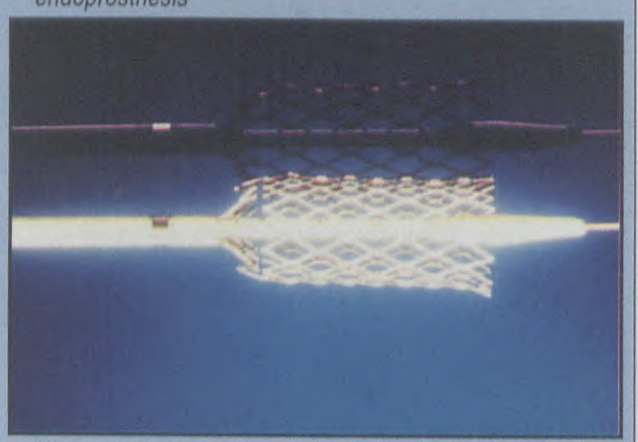

(a) Partial release of the stent after withdrawal of the outer sheath.

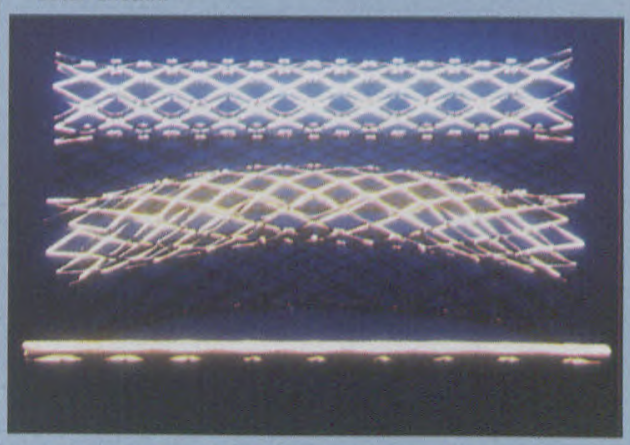

(b) The fully deployed stent. Note flaring of both ends. (Reproduced with permission from Isis Medical Press, Oxford)

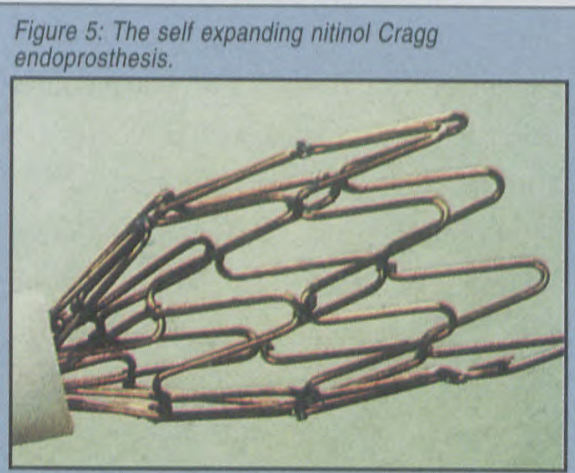

(a) The partially deployed stent emerging from the introduction sheath.

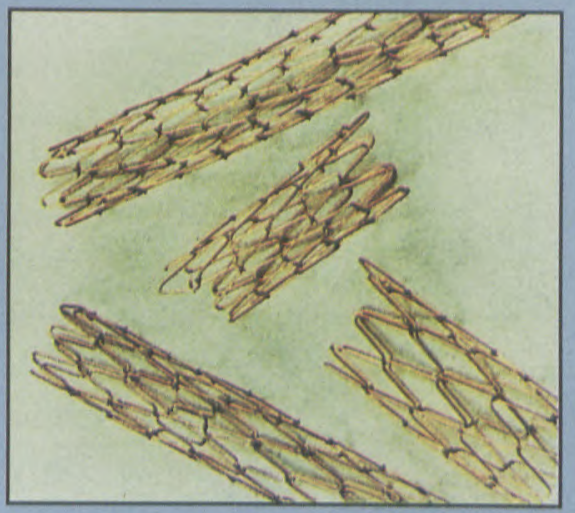

(b) The fully deployed stent. Note the sutures which hold together the nitinol filaments. (Reproduced with permission from Isis Medical Press, Oxford) tube of nitinol with slightly flared ends to reduce the risk of migration. It is highly radio-opaque and undergoes minimal shortening. Itcan be repositioned during deployment as long as no more than $30 \%$ of the total length has been deployed, which aids accurateplacement. ${ }^{7.8}$

The Cragg stent is constructed of a spiral of back and forth bends of a single nitinol filament held by a suture (Figure 5b). Infusion of cold saline during introduction through the introducer sheath keeps the wire maintained in the soft constrained state and aids placement. A covered stent (the Cragg Endopro) with ultrathin dacron sutured to the nitinol is also available (Figure6).

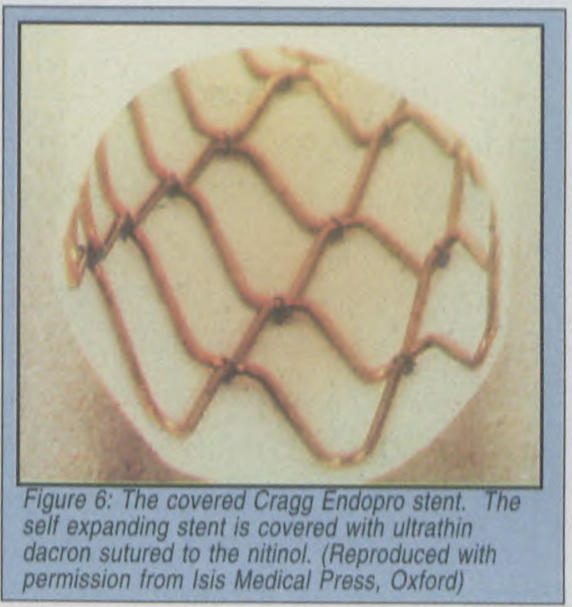

\section{Gianturco Zmetallic} endoprosthesis

An uncovered Gianturco Zstent is availablefor biliary, venous and tracheobronchial applications and a polyethylene covered stent is available for oesophageal use. An uncovered endoprosthesis is also available for use in the coronary arteries. The stent is made of stainless steel which is bent into a zigzag and joined at the ends forming a cylinder $^{9}$ (Figure 7). This is then compressed and loaded into a catheter. Deployment is by pushing the stent out of the lumen of the catheter into the vessel where re-expansion will occur. The final size and expansibility depend on the diameter of the 


\section{The use of metallic endoprostheses in interventional radiology}

\section{from page 9}

wire and the angle and number of bends in the wire. The initial stents were short and rigid and various developments -

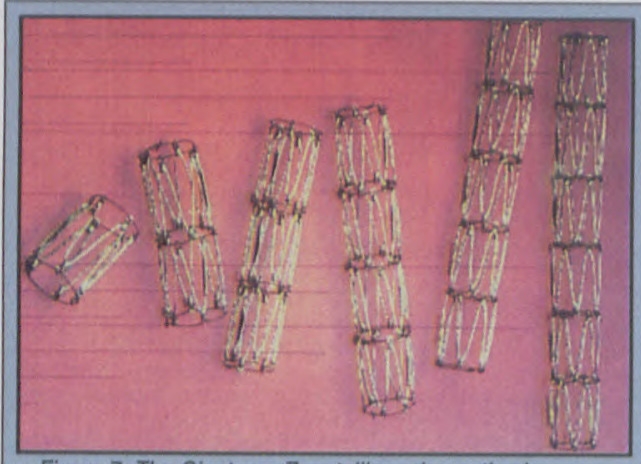

Figure 7: The Gianturco Z metallic endoprosthesis.

double stents for increased flexibility and siliconised stents for reduction of tumour ingrowth-have been made.

\section{Wallstent self expanding endoprosthesis}

This is a self expanding stent with a cylindrical braided structure with variations in design depending on the application. The stent is able to conform to the shape of the vessel, the flexiblity being attributed to its design which does not include any cross points (Figure 8). The stent is elongated for delivery on a narrow system and shortens during deployment dependent on the final diameter. This can make accurate placement difficult but it is possible to reposition the stent while it is only partially deployed. There has been rapid development of the Wallstent since 1989 and systems are currently available for vascular, ${ }^{10}$ biliary, ${ }^{11}$ oesophageal, ${ }^{12}$ tracheobronchial ${ }^{13}$ and TIPS ${ }^{14}$ use, each with differing properties and delivery systems.

The use of these various stents in differing applications will be discussed - however the final choice is often dependent on personal preference and familiarity with the delivery systems.

\section{Use of metallic endoprostheses in the vascular system}

\section{The lower limb}

Most experience has been gained within the vascular system of insertion of metallic stents in theiliac arteries. Balloon expandable and self expanding stents have longterm patency rates of $64-95 \%, 2,15,16,17 \mathrm{~A}$ study including 239 patients showed a 54 month patency rate of $81.5 \%$ with a significant difference in patency rates at 4 years between stented stenoses ( $82.9 \%)$ and stented occlusions (76.3\%). ${ }^{18}$ Both short stenoses and long occlusions have been successfully treated and several studies have shown long term patency rates to be better than percutaneous transluminal angioplasty (PTA) alone. PTA patency rates for aortoiliac lesions at 2 years are approximately $80 \%$ and at 5 years $72 \% .{ }^{19}$ A randomised trial of PTA vs iliac stenting with the Palmaz stent has shown stenting to be superior giving a better morphological response and lower trans-stenotic pressure gradient with fewer technical failures and fewer complications. ${ }^{20}$ Stenting has this advantage because of the high resistance of the stent to the collapse of the vesselwall. In addition the wall of the stent holds any dissection or plaque fracture away from the vessel lumen. Longer occlusions for which PTA is frequently unsuccessful, because of the collapse of thrombogenicmaterial into the opened lumen and subsequent thrombosis, can bestented with a long term success in approximately $76 \%$ of patients ${ }^{18}$ (Figure 9a-b). This technique can be ex-

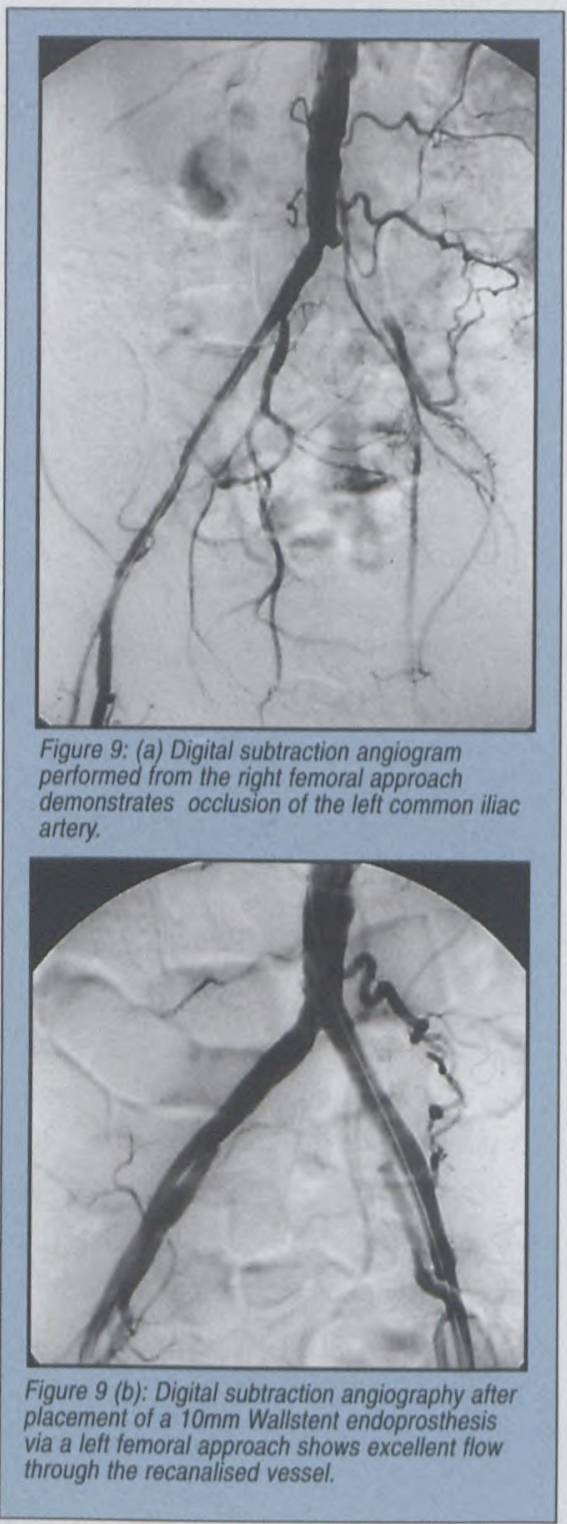

tended to reconstruct the aortic bifurcation in cases of Leriche syndrome (Figure 10ab). Early occlusion rates are higher in occlusions (5-6\%) than in short stenoses (1-2\%) and careful anticoagulation post stenting is particularly important here. Local complications of inguinal haematoma and pseudoaneurysm at the puncture site are reported to have an increased incidence when metallic stents are used compared to PTA alone due to the larger size introducer systems. These can be minimised with the 


\section{from page 10}

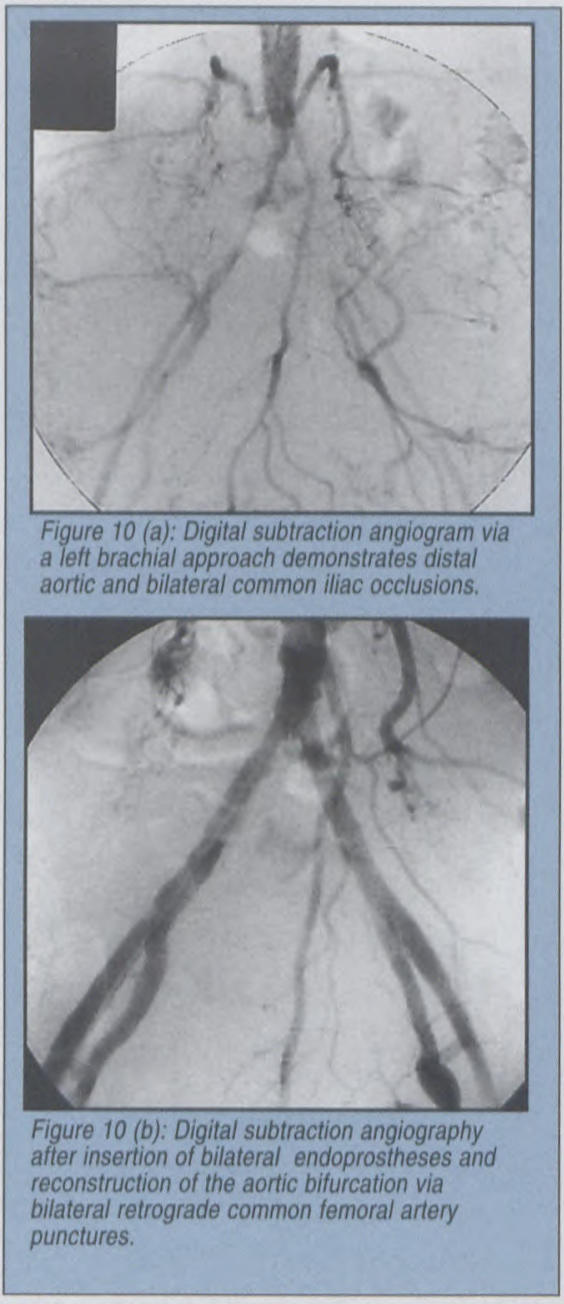

Wallstent which has a smaller diameter delivery system $(7-9 \mathrm{~F})$ than the Palmaz stent (8-10F). ${ }^{2}$ The FDA trial of the Wallstent included 130 iliac and 91 proximal femoral stents and showed a $96.4 \%$ primary angiographic success and a primary success rate of $88-96 \%$ with no significant difference between stenoses and occlusions. The 6 month patency rate was $77 \%$ with a complication rate of $16 \%$, although the majority were minor complications with only $2.7 \%$ requiring surgery.

There is no one specific clinical indication for stenting in the iliac vessels. The clinical situation, technical aspects e.g. site and configuration of thelesion, and the post angioplasty results need to be considered. In our institution we have evolved our own guidelines for stent placement within the iliac vessels (Table I), which includes aneurysmal disease (Figure 11).
Placement of stents in the distal vessels of theleg is generally less successful because of the smaller size of the vessels and the increased turbulence, particularly in the adductor canal. Restenosis rates are 30-40\% in trials using the Strecker stent, which is thought to be a consequence of intense endothelial hyperproliferation. ${ }^{21}$ Wedo not routinely use stents below the inguinal

\section{Table l: Indications for the insertion of metallic stents in the iliac vessels}
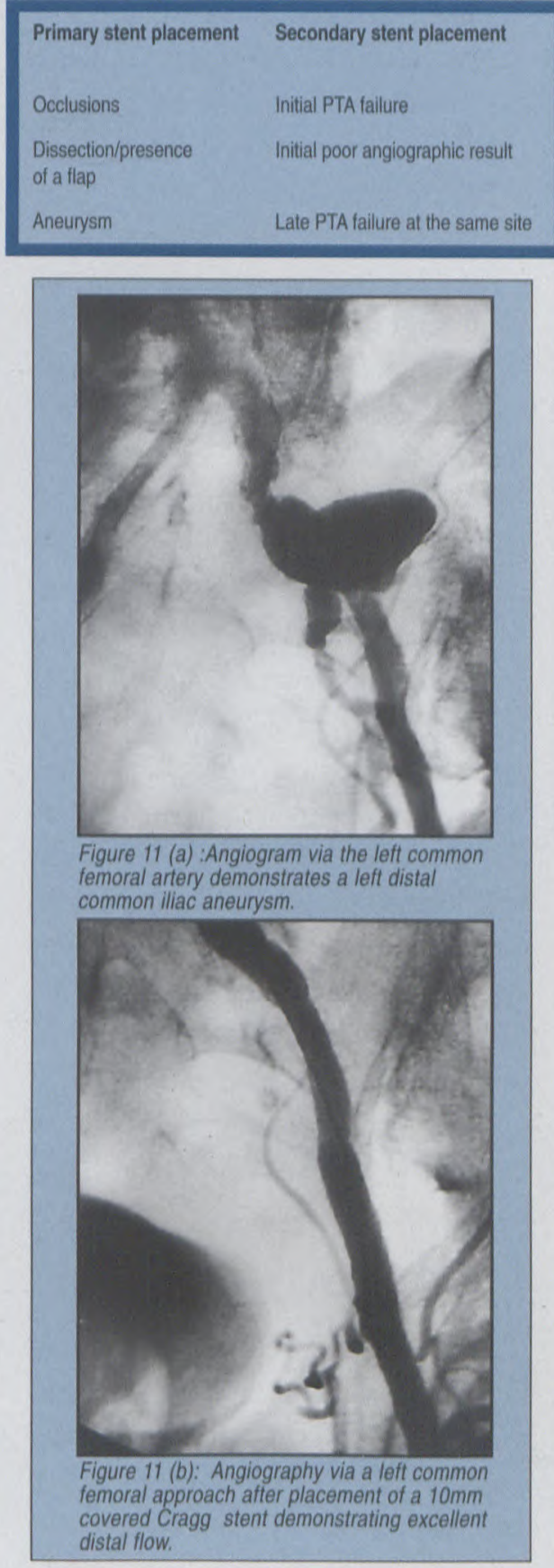

ligamentexceptinselected cases. Suggested indications are acute dissection producing occlusion that cannot be controlled by repeated PTA, reocclusion of a vascular segment which has been opened by PTA due to vascular wall deficiency, and exceptionally in cases of persistent restenosis after PTA with expected imminent restenosis.

\section{Renal arteries}

In the renal vessels stents may be used in limited circumstances as restenosis occurs angiographically in $20-39 \%$ \% 22,23 patients and further surgical management is difficult. Most experience has been with the Palmaz stent although other systems have been used including theWallstent and the Memotherm stent. Suggested current indications are failure of initial angioplasty with residual stenosis $>20 \%$, renal artery dissection post PTA, restenosis after PTA, distal based flaplike plaque, or in patients who are unsuitable for surgical revascularisation. The accurate positioning of the stent is imperative as the stent must not extend into the aorticlumen.

\section{Coeliac and superior mesenteric arteries}

The mortality of acute arterial occlusion in the abdominal visceral arteries (coeliac, superior and inferior mesenteric) is between 70 and $90 \%{ }^{24}$ and the postoperativemortality 3-20\%. ${ }^{25}$ PTA of mesenteric vessels has a primary success rate of $90 \%$ with redilation required in $50 \%$ of cases.$^{26}$ Stenting of mesenteric vessels requires a highly flexible stent because of the numerous curves between the puncture site and the site of deployment. Because of this the brachial approach may be easier to negotiate. We have used the Palmaz stent with good radiological and clinical results (Figure 12a-b). In our opinion the only indication for stent placement is failed PTA in a patient who is inoperable or a poor operative risk. This agrees with the limited amount of information in the literature. ${ }^{27,28}$ 


\section{The use of metallic endoprostheses in interventional radiology}

from page 11

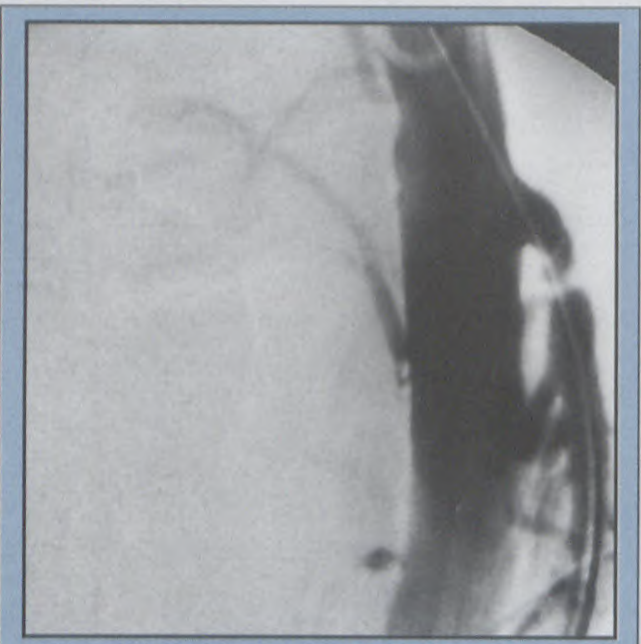

Figure.12 (a): Angiogram via a left brachial approach demonstrates tight occlusion at the origin of the superior mesenteric artery.

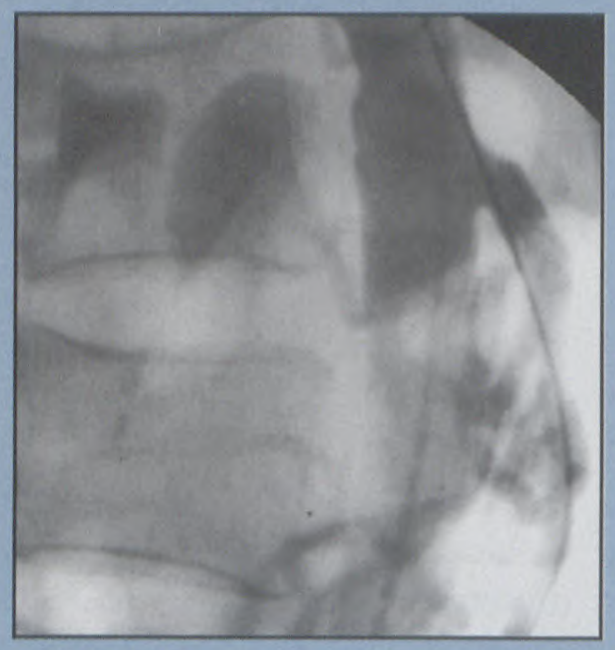

Figure 12 (b): Angiogram after placement of a $9 \mathrm{~mm}$ Palmaz stent with a good radiological result.

\section{Supra-aortic arteries}

The Wallstent has been successfully used in the supra-aortic vessels both as primary procedure and in restenosis after PTA. PTA is a high risk procedure in these vessels because of the risk of embolisation, particularly for the recanalisation of occluded vessels. In a series of 42 carotid stents $^{29} 2$ patients had transient ischaemic attacks and there were no long term neurological deficits. The rate of recurrent stenoses in these vessels is low, this is probably because of the large vessel size and high flow. The Wallstent is used preferentially in this region because it is flexible and self expanding so the artery is not occluded at any time during deployment. No migration of the Wallstent is reported; it is thought that theStrecker stent may potentially migrate if the ends are not sufficiently overdilated for anchorage . $^{30}$

\section{Aorta}

The first report of endoluminal stent placement for aortic aneurysm repair was in $19911^{30}$ Sincethen stentshavebeen placed successfully in both the thoracic and abdominal descending aorta ${ }^{31}$ Early experience with the tube stent-graft combinations required the aneurysm to be in the descending aorta with well defined necks at both ends, not tortuous, with no sharp angles and with no side branch involvement. However more recently bifurcated stent-graft combinations have become available increasing the number of cases suitablefor endoluminal grafting. Both balloon expandable and covered stents have been used, these have been custom made to fit the individual characteristics of each aneurysm. Careful preprocedure imaging in each patient is a prerequisite so that the stent-graft combination conforms to the aneurysm exactly. Leakage at the upper or lower end can preventsealing of the aneurysm and enable continued expansion. Reported complications include difficulty of delivery of the large introducer system (up to 24 french), stent migration during deployment which can be partially overcome by lowering the systolic blood pressure during release, and relatively minor complications of pleuritic chest pain and pleural effusion. ${ }^{32}$ Transient weakness of the lower limbs has also been described.$^{32}$

\section{Venous stents}

PTA for the treatment of venous stenoses has been used with limited success and high rates of restenosis. ${ }^{33} \mathrm{How}-$ ever venous stenting has proved valuable in malignant disease, ${ }^{34,35}$ stenting in benign disease should only be performed after detailed discussion with clinical colleagues. It is important to distinguish between benign 'benign' disease and benign 'malignant' disease, where life expectancy is short although no strictly malignant disease is present. Self expanding stents (Wallstent, Gianturco) are most commonly used in tumour related stenoses and predilatation is recommended. Relieffrom obstructive symptoms, for example in superior vena cava obstruction, after stenting occurs within hours. Brachiocephalic stenosis complicating haemodialysis has a high restenosis rate following PTA. ${ }^{36}$ Stenting here may give more permanent relief although restenosis in adjacent areas often occurs. ${ }^{37,38}$

\section{Metal stents in the oesophagus}

The use of metal stents in the oesophagus is largely confined to the palliation of malignant disease. Balloon dilatation is generally successful in the treatment of benign strictures in the majority of cases and self expanding metallic stents should only be used with caution and after detailed discussion with clinical colleagues. ${ }^{39}$ Self expanding metal stents can be used as firstline treatment for inoperablemalignant strictures and have distinct advantages over other palliative methods. Radiotherapy may relieve symptoms but may take 8 weeks to be effective. ${ }^{40,41}$ Plastic endoprostheses are cheap but require general anaesthesia for placement and usually only allow a liquid diet. ${ }^{42}$ Endoscopic laser therapy is safe and effective but needs repeating every $4-8$ weeks. ${ }^{43}$ The metallic stents commonly used in the oesophagus are the Ultraflex, Gianturco, andWallstent (Figure 13). All areselfexpanding, with different expansile radial forces. Balloon dilatation up to $12 \mathrm{~mm}$ is advised prior to stent placement and if this is performed the Gianturco and Wallstent usually maintain 


\section{from page 12}

patency of the oesophageal lumen without further intervention. However post placement dilatation is often required with the Ultraflex as its radial expansile force is less. Various diameters and lengths of stent are available to match the pre procedure contrastassessment of the stricture. Therelease

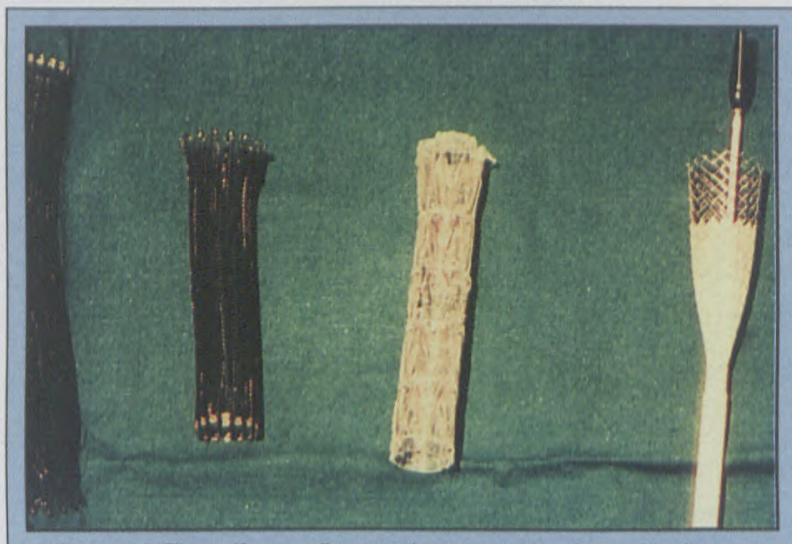

Figure 13: The self expanding metal stents commonly used in the oesophagus include the nitinol Elastalloy stent (left), the polyethylene covered Gianturco stent (centre), and the polyurethene covered Wallstent (right). confined to lesions where the lower end of the stent lies above the cardia. Covered stents are the stent of choice where there is perforation or fistulation (Figure 14a-b). Laser can be used to treat tumour ingrowth which cannot be relieved by passage of an endoscope. A second stent can be placed where tumour overgrows the end of the stent. Manufacturers are currently improving designs to minimise the problems of migration and tumour ingrowth.

Using similar principles stents can be placed to relieve obstruction in the duodenum and proximal small bowel.

\section{Tracheo- bronchial stenting}

mechanisms for the different devices are similar but have a number of important differences. The Ultraflex is compressed by a gelatine coating which dissolves on contact with secretions within thelumen of the oesophagus. The Telestop delivery system of the Wallstent has 3 coaxial shafts the outer of which can be readvanced over the partially released stent to allow repositioning during the procedure. The Gianturco device has a cord which needs to be severed once the stent is in the required position. Technical success using these stents is near $100 \%$ and improvement in dysphagia $90-100 \% .44,45$ Stent related mortality is $0-6 \%$. Oesophageal perforation secondary to the procedure is rare, mortality is more commonly a result of GI haemorrhage or aspiration. Morbidity includes stentmigration, tumouringrowth and overgrowth, and foodimpaction. Gastro-oesophageal reflux is common especially where the end of the stent lies in the fundus of the stomach. Tumour ingrowth can be minimised by the use of covered stents but the migration rate of these is higher and their use is best
Stenting for major airway obstruction in malignant disease in the trachea and bronchi has only become possible recently with the advancement of the development of metallic stents. Clinical assessment prior

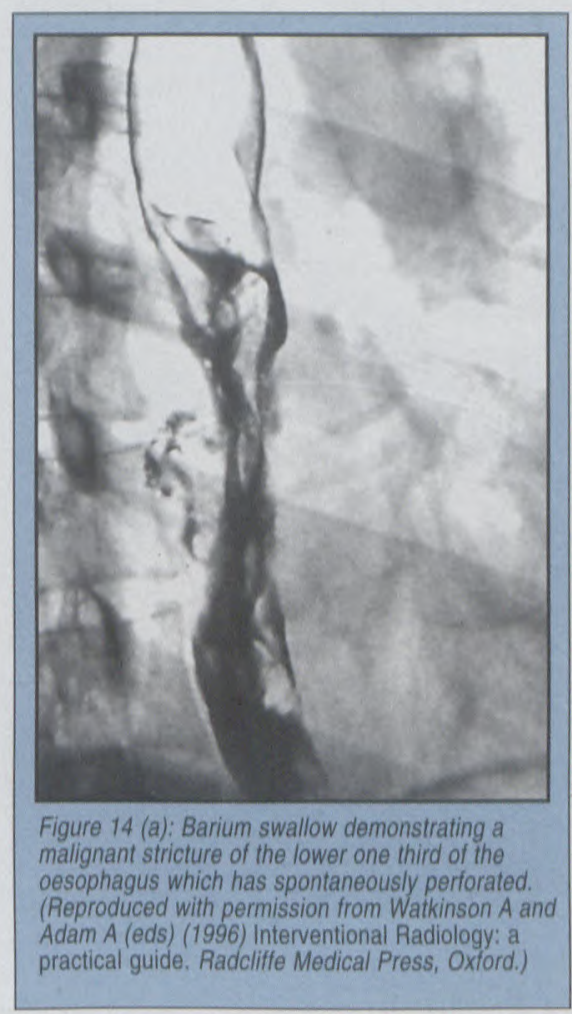

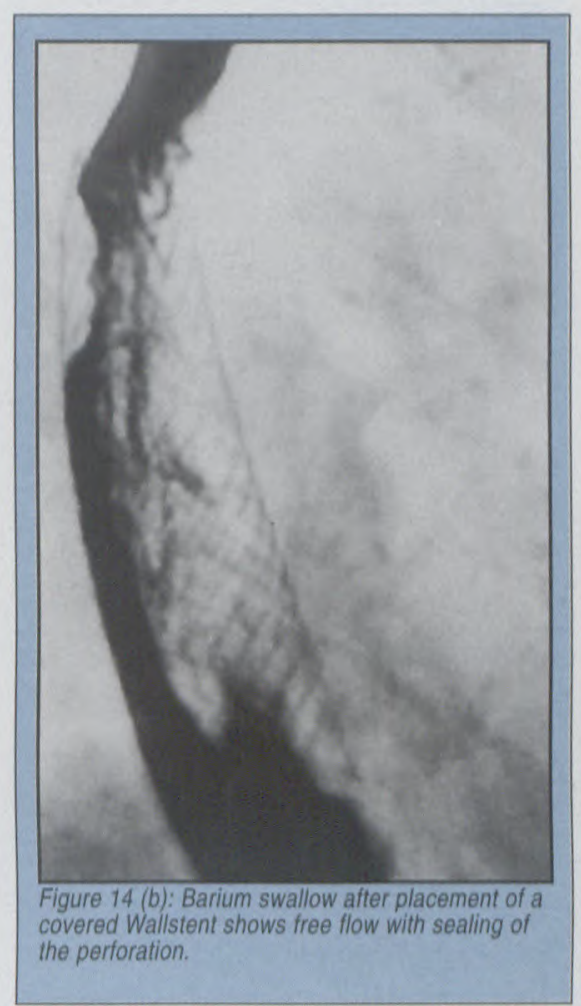

to stenting is vital as recanalisation of the airway may not produce significant improvementin respiratory symptomsif there is distal disease. Silicone stents had been used previously but they can only be deployed in the major airways, tend to migrate and occlude due to mucus impaction. ${ }^{46} \mathrm{Of}$ the metallic stents available the Gianturco has been used most widely but is not without problems ${ }^{47}$ Distal migration may occur as the stent is pushed out of the sheath and tumour ingrowth may occur in uncovered stents while covered stents cannot not be used across airway bifurcations. Complication rates of up to $30 \%$ are recognised and a case of tracheal perforation has been reported. ${ }^{48}$ The Wallstent has advantages over the Gianturco in that it is easier to reposition during deployment, migrates less frequently and has less tumour ingrowth whileallowing aeration whereside branches are crossed. ${ }^{49}$ The nitinol stents eg. nitinol Memotherm are also achieving good results presumably because of their great rigidity whilst maintaining flexibility. ${ }^{50}$ 


\section{from page 13}

\section{Metal stents in the biliary system}

Percutaneous transhepatic biliary drainage is well established in benign and malignant biliary obstruction ${ }^{51}$ and is currently the procedure of choice if endoscopic methods fail. Historically plastic stents have usually been placed. These have the disadvantage of a high migration rate (3-6\%) and need frequent replacement. ${ }^{52,53}$ These problems may be overcome by the larger diameter of metal stents and the epithelialisation over the mesh preventing migration. Plastic stents occlude in most instances due to bile encrustation ${ }^{53}$ whilst occlusion in metallic endoprostheses is secondary to tumour ingrowth or overgrowth. This was significantin early studies, ${ }^{11}$ howevermore recent series, wherelonger stents have been placed to minimise the problem of overgrowth, have shown much lower occlusion rates (12\%). ${ }^{54,55}$ The only randomised trial of plastic versus metal stents ${ }^{53}$ demonstrated a lower reintervention rate using metal stents ( $12 \%$ vs $43 \%)$. Other advantages of metal stents mainly centre around the smaller size of the introducer sheath (7Fr-8Fr vs 12Fr for plastic stents) reducing local complication rates and enabling a one stage procedure to be performed. In our institution we routinely use metallic stents for clinical benefit to the patient in the short term (smaller introducer system, one stage procedure) and the long term (longer patency rates therefore reduced reintervention). In addition the randomised trial ${ }^{53}$ demonstrated a financial advantage due to reduced reintervention rate in the long term. A disadvantage of metal stents is that they cannot be removed after epithelialisation has occurred, and their use is therefore restricted to permanent stenting predominantly for the relief of malignant strictures. The role in benign strictures is limited to strictures that are resistant to repeated balloon dilatation and in whom surgery is inadvisable or unwanted. ${ }^{56}$ Most of the current literature refers to theWallstent, however the nitinol Memotherm stent is being increasingly used(Figure 15a-d).

\section{TIPS \\ (Transjugular Intrahepatic Portosystemic Shunt)}

The development of metal stents has enabledTIPS to become established in the treatment of variceal haemorrhage and portal hypertension (Figure 16). 57,58,59 Contraindications to this procedure

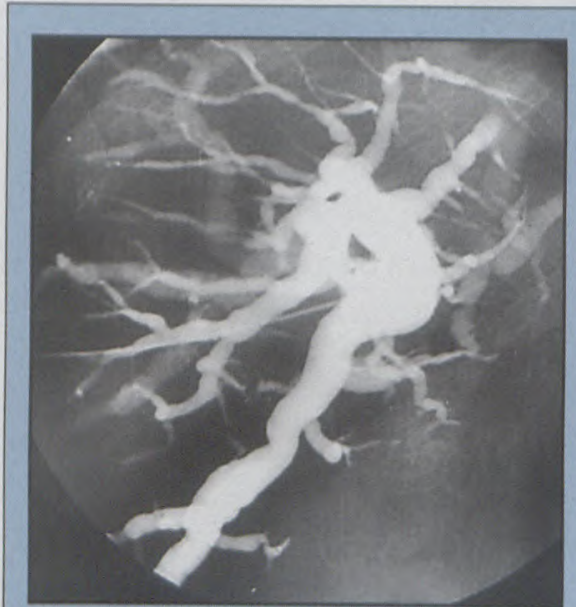

Figure 15 (a): Percutaneous transhepatic cholangiogram demonstrating dilatation of the intrahepatic biliary tree.

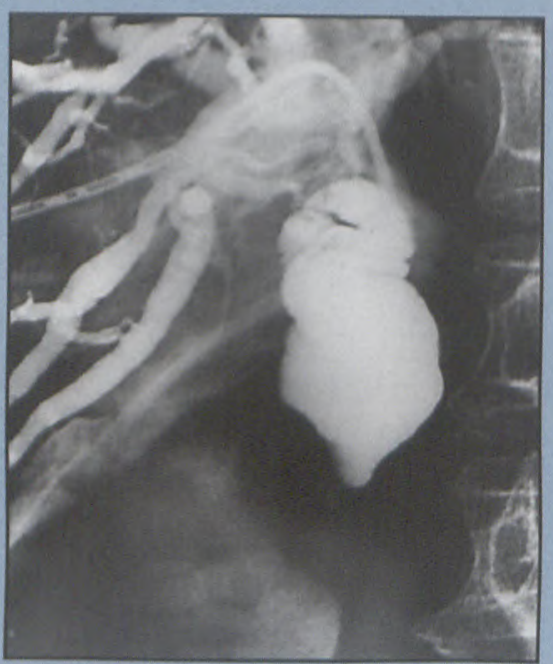

Figure 15 (b): This was confirmed to be due to carcinoma of the head of the pancreas with obstruction at the level of the lower common hepatic duct.

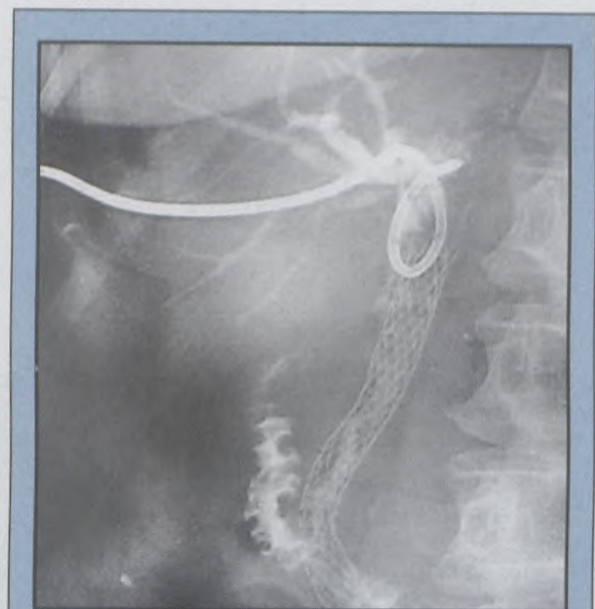

Figure 15 (c): A 10mm Memotherm stent has been introduced percutaneously with a safety catheter left in for 24 hours.

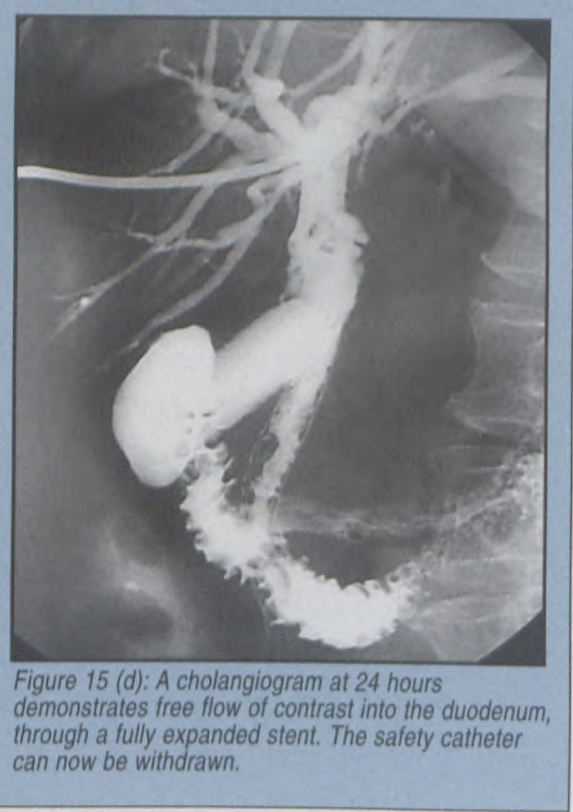

include raised right heart pressure, sepsis, acute liver failure or extensive malignancy in the proposed transhepatic path. The technique involves dilatation of the intrahepatic tractbetween the hepatic and portal veins and the placement of an expandablemetallic stent. Thisreduces the pressure gradient between the portal vein and hepatic vein to $10-15 \mathrm{~mm} \mathrm{Hg}$ which is sufficient to reduce bleeding but not induce encephalopathy. A $10-12 \mathrm{~mm}$ Wallstent or Memotherm endoprosthesis is the stent of choice. Technical success is 95-100\%. ${ }^{60,61,62}$ Procedural mortality is $1-10 \%$, usually from capsular rupture. ${ }^{60,61,62}$ Shunt malfunction may occur as a late 


\section{from page 14}

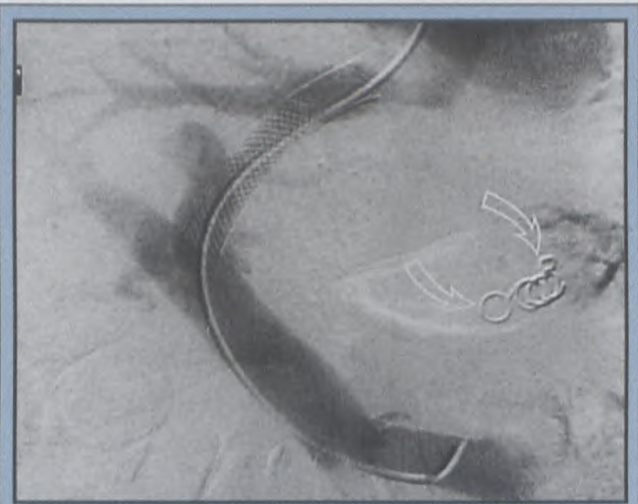

Figure 16: TIPS (Transjugular Intrahepatic Portosystemic Shunt)

Digital subtraction venography via a catheter introduced from the right internal jugular vein and positioned transhepatically in the portal vein. A 10mm Wallstent endoprosthesis has been positioned to create a shunt between the left portal vein and the right hepatic vein. There is excellent flow through this shunt into the right atrium. Embolisation coils are noted (arrows) following embolisation of the coronary vein. (Reproduced with permission from Watkinson $A$ and Adam A (eds) (1996) Interventional Radiology: a practical guide. Radcliffe Medical Press, Oxford.)

complication in $25-40 \%$ and is usually due to intimal hyperplasia with reintervention rates rising to $68 \%$ at 2 years. ${ }^{60}$ Regular surveillance with Doppler and directcatheterisation is necessary. ${ }^{63}$ Shunt malfunction can be treated with balloon dilatation or placement of a second stent with good long term results. TIPS is particularly valuable for patients awaiting liver transplant and does not increase the operative difficulty in the short term (3-6 months.)

\section{Conclusion}

Metal stents are now being used for a wide number of clinical applications in many areas. This incorporates restoration of patency in many vessels in the vascular system with good long term patency and palliation of numerous malignant conditions in which a compromised 'lumen' results in poor quality of life in many instances and a shortened life span in others. This is largely due to the advances in stent research and design over the past decades and the availability of a range of different stents for these applications. This has produced an improvement in patency rates with, in many instances, reduced mortality and morbidity. The future is focussed on further improved stent design. Recent research work has centered on reducing intimal hyperplasia, particularly in the vascular system, using coated stents ${ }^{64}$, exploitingmetallic properties to reduce cell growth locally ${ }^{65}$ and even the use of local irradiation. ${ }^{66}$ We look foward to the continued application of these devices as they become available.

\section{References}

1. Dotter CT Transluminally placed coil spring endarterectomy tube grafts: long term patency in canine popliteal artery. Invest. Radiol. 1969;4:327-332

2. Palmaz JC, Schatz RA, Richter G et al. Intraluminal stenting of iliac artery stenosis: Preliminary report of a multicentre trial. Circulation 1988;78[suppl 11]:11-415

3. Richter GM, Palmaz JC, Noeldge G et al. Der transjugulare intrahepatische portpsystemische stentshunt [TIPSS] Radiologe 1989;29:406-41]

4. Strecker EP, Liermann D, Barth KH et al. Expandable tubular stents for the treatment of arterial occlusive disease: experimental and clinical results. Radiology 1990;175:97

5. Hearn JA, Robinson KA, Roubin. In vitro thrombus formation of stent wires: Role of metallic compostion and heparin coating [abstract]. JACC 1991;17:302A

6. Tietze H, Phasenubergange mit memory-effekt. 1985. Verlag F. akademische Schriften Frankfurt.

7. Fredrich JM, Vogel J, Goerich J. Usefulness of a new nitinol stent in the treatment of biliary obstructions. Radiology 1995;197[P]:696:241

8. Stark EE, Dukiet C, Truss J et al. Strecker tantalum and Memotherm nitinol stents: comparison of clinical data. Radiology 1995;197[P]:1160:316

9. Wright KC, Wallace $\mathrm{S}$, Charnsaangavej $\mathrm{C}$ et al. Percutaneous endovascular stents: An experimental evaluation. Radiology 1985;156:60-72

10. Watkinson AF, Hansell DM. Expandable Wallstent for the treatment of obstruction of the superior vena cava. Thorax 1993;48:915-920

11. Gillams A, Dick R, Dooley JS et al. Self expandable stainless steel braided endoprostheses for biliary strictures.Radiology 1990;174:137-140

12. Watkinson AF, Ellul J, Entwistle Ket al. Oesophageal carcinoma: Initial results of palliative treatment with covered self expanding endoprostheses. Radiology 1995; 195:821-827

13. Rousseau H, Dahan M, Laugue D et al. Self expanding endoprostheses in the tracheobronchial tree. Radiology 1993;188:199-203

14. La Berge, Ring EJ, Gordon RC et al. Creation of transjugular intrahepatic portosystemic shunts with the Wallstent endoprosthesis: results in 100 patients. Radiology 1993;187:413-420

15. Strunk HM, Schild HH, Dueber C et al Reobstruction after iliac artery stent placement: fre- quency and methods of treatment [abst. 108]. Radiology 1993;189[Suppl P]:293

16. Strecker EP, Hagen B, Liermann D, et al. Iliac and femeropopliteal vascular occlusive disease treated with flexible tantalum stents. Cardiovasc Intervent Radiol 1993:16:158-164

17.Zollikofer Cl, Antonucci F, Pfyffer M et al. Arterial stent placement with use of the Wallstent; midterm results of clinical experience. Radiology 1991;179:449456

18. Strecker EP, Hagen B, Liermann D et al. Long term results following treatment of $\mathrm{iliac}$ artery stenoses and occlusions with flexible tantalum stents. In Liermann D, ed. 'Stents-State of the Art and Future Developments.' Morin Heights, Canada: Polyscience Publications Inc., in conjuction with Boston Scientific Corporation, Watertown,MA.USA. 1995, 23-29

19. Beck G, Katzen B, Dake M. Noncoronary angioplasty. Radiology 1989;170:921-940

20. Richter GM, Noldge G, Thomas Ret al. 1995. Further analysis of a randomised trial comparing primary iliac stenting and percutaneous transluminal angioplasty. In: Liermann D, ed.'Stents-State of the Art and Future Developments.' Morin Heights, Canada: Polyscience Publications Inc, in conjunction with Boston Scientific Corporation, Watertown, MA. USA 1995,30-35

21. Liermann D. Use of the Strecker stent in lower extremity arterial vessels: a long term follow up. In: Liermann D, ed. 'Stents-State of the Art and Future Developments.' Morin Heights, Canada: Polyscience Publications Inc, in conjunction with Boston Scientific Corporation, Watertown, MA. USA. 1995,50-57

22. Rees CR, Palmaz J, Becker GJ et al. Palmaz stents in atherosclerotic stenoses involving the ostia of renal arteries: preliminary report of a multicentre study. $\mathrm{Ra}$ diology 1991;181:507-514

23. Hennequin LM, Joffre FG, Rousseau HP et al. Renal artery stent placement:long term results with the Wallstent endoprosthesis. Radiology 1994;191:713-719

24. Jenson CB, Smith GA.A clinical study of 51 cases of mesenteric infarction. Surg, 1956;40:930

25. Rapp JH, Riely LM, Quaford PG. Durability of endarterectomy and antegrade grafts in the treatment of chronic visceral ischaemia. JVasc. Surg. 1986;4:338344

26. Odurny A, Sniderman KW, Colapinto RF. Intestinal Angina: Percutaneous transluminal angioplasty of coeliac and superior mesenteric arteries. Radiology 1988; 165-167

27. Liermann D, Strecker EP, Jacobs V et al. Severe angina abdominalis, treatment by implantation of a highly flexible tantalum Endoprosthesis. Angiology 1992:43:275

28. Liermann D, Strecker EP.Tantalum stents in the treatment of stenotic and occlusive disease of abdominal vessels. In: Liermann D, ed.' Stents-State of the An and Future Developments.' Morin Heights, Canada: Polyscience Publications Inc, in conjunction with Boston Scientific Corporation, Watertown, MA. USA. 1995,127-133

29. Parodi JL, PalmazJC, Barone HD etal. Transfemoral intraluminal graft implantation in abdominal aortic aneurysms. Ann. Vasc. Surg. 1991:491-499

to page 16 


\section{The use of metallic endoprostheses in interventional radiology}

\section{from page 15}

30. Mathias K. Stent placement in supraaortic artery disease. In: Liermann D, ed. 'Stents-State of the Art and Future Developments.' Morin Heights, Canada: Polyscience Publications Inc, in conjunction with Boston Scientific Corporation, Watertown, MA. USA. 1995, $87-92$

31. May J,White GU, YuW.et al.Advantages and limitations of intraluminal grafts for thoracic and abdominal aortic aneurysm. Angiology 1993;Suppl 4:21

32. May J,White G, Waugh R et al. Endoluminal stent grafts for intrathoracic and abdominal aortc aneurysms. In: Liermann D, ed.'Stents-State of the Art and Future Developments.' Morin Heights, Canada: Polyscience Publications Inc, in conjunction with Boston Scientific Corporation, Watertown, MA.USA. 1995, 3-6

33. Wilms G, Baert AL, Nevelsteen A et al. Balloon angioplasty of venous stricture. JBR-PTR 1989;72:273याग

34. Capek P, Cope C. Percutaneous treatment of superior vena cava syndrome. AJR 1989;152:183-184

35. Rosch J,Uchida BT, Hall LD et al. Gianturco-Rosch expandable Z stents in the treatment of superior vena cava syndrome. Cardiovasc. Intervent. Radiol. 1992:15:319-320

36. Canherwegher Jl, Cabolet P, Dhaene M etal. Complications related to subclavian catheters for heamodialysis. Am. J. Nephrol. 1986;6:339-345

37. Irving JD, Dondelinger RF, Reidy JF et al. Gianturco self expanding stents: clinical experience in the ven cava and large veins. Cardiovasc. Intervent. Radiol.1992;15:328-333

38. Zollihofer CL, Antonucci F, Gluckmann G et al. Stents in venous vessels. In:Liermann D ed. 'Stents-State of the Art and Future Developments.' Morin Heights, Canada: Polyscience Publications Inc., in conjunction with Boston Scientific Corporation, Watertown, MA USA. 1995,73-78

39. Adam A, Watkinson AF, Dussek J, Boerhaves syndrome: to treat or not to treat by insertion of a metallic stent JVIR 1995:6:74l-746

40. Hishikawa Y, Kamikonya N, Tanakas S et al. Radiotherapy of esophageal caricinoma: role of high dose rate intracavity irradiation. Radiother. Oncol. 1987;9-13

41. Caspers RJ, Welvaart K, Verked RJ. The effect of radiotherapy on dysphagia and survival in patients with oesophageal cancer. Radiother. Oncol. 1988:12:15-23
42. Brown SG. Endoscopic laser therapy for esophageal cancer.Endoscopy 1986;18:26

43. Atkinson M, Ferguson R, Parker GC. Tube introducer modified Celestin tube for use in palliative intubation of esophago-gastric neoplasms at fibre optic endoscopy. Gut 1978;19:669

44. Watkinson AF, Ellul J, Farrugia M et al. Plastic covered metallic endoprostheses in the managment of oesophageal perforation in patients with oesophageal carcinoma. Clin. Radiol. 1995;50:304-309

45. Ellul J,Watkinson AF, Adam A. Preliminary experience in the palliation of malignant oesophageal dysphagia with metallic stents. Br. J.Surg. 1995;82:12

46. Migazawa T, Doi M, Mineshita M et al. The placement of the Dumon stent for airway stenosis. J. Jap. Soc. Bronchology 1993;15:749-56

47. Do Y, Song H, Lee H, et al. Esophagorespiratory fistula associated with oesophageal carcinoma: treatment with a Gianturco stent tube. Radiology 1993 187:673677

48. Rauber K, Franke C, Ray,WS et al. Venedurchwandering bei Gianturco-Wallace stents. Radiology 1990;141:293

49. Liermann D, Lorcher U, Rauber K et al. Stents in the trachiobronchial system - first results. Eur. Radiol 1991.55

50. Liermann D, Rust M. First experiences with a new memory metallic endoprosthesis in the tracheobronchial system. 260-265

51. Ring EJ. Radiologic approach to malignant biliary obstruction:review and commentary. Cardiovasc. Interven. Radiol. 1990;13:217-222

52. Davids PHP, Groen AK, Rauws EAJ et al Randomized trial of self expanding metal stents versus polyethelene stents for distal malignant biliary obstruction. Lancet 1992;340:1488-1492

53. Mueller PR, Ferrucci JT,TeplickSket al. Biliary stent endoprosthesis: analysis of complications in $113 \mathrm{pa}$ tients. Radiology 1985;156:637-639

54. Lameris JS, Stoker J, Nijis Hg et al. Malignant biliary obstruction: percutaneous use of self expandable stents. Radiology 1991;179:703-707

55. Adam A, Chetty N, Roddie Met al. Self expandable stainless steel endoprostheses for the treatment of malignant bile duct obstruction. AJR 1991;156:321-325
56. Lammer J, Deu E. Percutaneous managment of benign biliary strictures. In Kadir S, ed. Current Practice of Interventional Radiology. Philadelphia: Decker Inc;1991;550-553

57. Cremer M, Sugai B, Delhaye M et al. Expandable pancreatic metal stents [Wallstents] for chronic pancreatitis: first world series [abstr.] Gastroeneterology 1990;98:A215

58. Dondelinger RF, Kurdziel JC. Percutaneous placement of expandable metal stents in the main pancretic duct. Sem. Intervent. Radiol. 1991:8:316-320

59. Kozarek RA. Pancreatic stents can induce changes consistent with chronic pancreatits. Gastrointest. Endosc 1990:36:93-95

60. Richter GM, Noeldge G, Roeren TK et al. Five year results of TIPS: technical standard and long term clinical efficiancy. JVIR 1990;5:20-21

61. Rossle M, Haag K, Ochs A et al. The transiugular intra-hepatic portosystemic shunt procedure for variceal bleeding. N. Engl.J.Med. 1993;330:165-171

62. Rosseau H, Vinel JP, Bilbao JI et al. Transiugular intrahepatic portosystemic shunts using the Wallstent endoprosthesis: a follow up study. Cardiovasc. Intervent. Radiol. 1994;17:7-11

63. Ferral H, Foshager MC, Bjarnason $\mathrm{H}$ et al. Early sonographic evaluation of the transjugular intrahepatic portosystemic shunt TIPS. Cardiovasc. Intervent. Radiol. 1993; $16[5]: 275-9$

64. Machan LS, Jessurun MD, Hunter W et al., Angiogenesis Inhibitor-Coated Metallic Stents in the porcine bile duct: Prevention of Benign Reactive Overgrowth. Radiology 1995;197[P]:695:241

65.Schmitz-RodeT,Brune M,Hoffmeidter Ket al.High frequency induction heating of stents: An approach to control intimal hyperplasia and tumour ingrowth. $R a$ diology 1995;197[P]:1555:382

66. Hehrlein C, Gollan C, Donges Ket al., Low dose radioactive endovascular stents prevent smooth muscle cell proliferation and neointimal hyperplasia in rabbits. Circulation 1995:92:1570-1575 